\title{
Hoarding behaviour in Xhosa patients with schizophrenia - prevalence and clinical presentation
}

T Ameer, $M B$ ChB

D J H Niehaus, MB ChB, MMed (Psych), DMed

L Koen, MB ChB, MMed (Psych)

C Seller, MB ChB, MMed (Psych), FCPsych

Department of Psychiatry, Stikland Hospital, Stellenbosch University, W Cape

S Seedat, MB ChB, MMed (Psych), FCPsych, PhD Medical Research Council Unit for Anxiety and Stress Disorders, Department of Psychiatry, Stellenbosch University, W Cape

Objective. Hoarding is commonly defined as the acquisition of and failure to discard possessions of little use or value, and is included as a symptom in the diagnostic criteria for obsessive compulsive personality disorder (OCPD) and obsessive compulsive disorder (OCD). However, it has also been observed in other clinical syndromes including schizophrenia. This study was conducted to investigate the prevalence and clinical presentation of hoarding behaviour in schizophrenia among Xhosa patients.

Method. The sample consisted of 102 patients, recruited as part of a larger genetic study in the Cape Town metropole between November 2004 and January 2005, diagnosed with schizophrenia or schizoaffective disorders according to the Diagnostic and Statistical Manual of Mental Disorders (DSM-IM) criteria. They were screened for clinically significant hoarding symptoms. If these were present, additional information on the phenomenology was obtained by means of a structured questionnaire. The Mini International Neuropsychiatric Interview (MINI) (screen and full version), the Yale Brown Obsessive Compulsive Scale (Y-BOCS) Checklist, Y-BOCS, Clutter Image Rating Scale (CIRS) and a structured questionnaire on hoarding were administered.

Results. Only four patients with schizophrenia were classified as hoarders. Although their clinical presentation resembled that of hoarders described elsewhere in the literature, they had low Y-BOCS scores and did not report other obsessive-compulsive symptoms.

Conclusion. Our results suggest that hoarding behaviour is not common in Xhosa patients with schizophrenia. Further investigation of protective factors for hoarding behaviour in the Xhosa population is warranted.
Hoarding has been defined as 'the acquisition of, and failure to discard, possessions that are useless or have limited value'. ' It is associated with marked distress and/or impairment in social and occupational functioning. In severe cases, living spaces become significantly cluttered so as to preclude the activities for which they were designed. ${ }^{2}$ The amount of clutter can also present a risk to the hoarder in terms of health, sanitation and fire hazards. ${ }^{1,3}$

Hoarding is currently classified as a symptom of obsessive compulsive disorder $(O C D)^{4}$ and obsessive compulsive personality disorder (OCPD). ${ }^{4}$ Estimates of the frequency of hoarding behaviour in OCD range between 18\% and 33\%. When present, compulsive hoarding seems to cause increased social impairment in patients with $O C D .^{5}$ Patients with $O C D$ who hoard have less insight, increased avoidant behaviour and pathological doubting, and more symptoms and greater OCD severity than non-hoarders. ${ }^{5}$ Several authors have sought to identify the phenotypical characteristics of hoarding behaviour. For example, in a study of 14 cases of hoarding, Greenberg .., 7 and Claire ef al. ${ }^{8}$ reported that all subjects shared the following characteristics: inability to resist hoarding compulsion, preoccupation with hoarding to the exclusion of work and family, diminished insight, little interest in receiving treatment, no attempt to curb their compulsion to hoard, and a repetitive pattern of behaviour. Hoarding behaviour has been noted in patients with dementia, autism, impulsive symptoms, Prader-Willi syndrome la congenital syndrome characterised by hyperphagia and compulsive self mutilation - these patients also have other classic symptoms of OCDI, and in patients with eating disorders ${ }^{9}$ and depression. ${ }^{10}$ However, the prevalence of hoarding in these disorders is largely unknown.

Repetitive behaviours, like hoarding, have also been described in schizophrenia. Tracy et al. ${ }^{11}$ investigated 9 repetitive behaviours in 400 patients with schizophrenia. Factor analysis suggested that a 5-factor model best represented the data, with '"bizarre use of objects" bizarre grooming and hoarding' representing 1 of the 5 factors. In patients with schizophrenia the underlying trigger for the hoarding behaviour may occur in response to delusions, e.g. fixed fears of theft and personal protection. 'The rate of OCD in schizophrenia has been reported to be between $7.8 \%$ and $31.7 \% .^{12-16}$ However, there are no large-scale prevalence studies of hoarding in this population. ${ }^{3}$ It is notable that in a recent study by Niehaus et al. ${ }^{17}$ the prevalence of $O C D$ was reported to 
be low $(0.5 \%)$ in a South African sample of Xhosa patients with schizophrenia.

The present study was carried out to investigate the prevalence of hoarding and to describe the clinical presentation of such behaviour in a sample of Xhosa-speakers diagnosed with schizophrenia. OCD has a significant genetic component, as evidenced by twin studies and family studies. ${ }^{18}$ This study was performed in a geographically similar and genetically homogeneous population, thereby reducing confounding factors such as genetic heterogeneity.

\section{Methods and scales}

\section{Subjects}

The sample consisted of 102 Xhosa patients with schizophrenia or schizo-affective disorder. Patients were recruited through a large genetics study in the Cape Town metropole (Western Cape, South Africal between November 2004 and January 2005. Patients eligible for inclusion in the genetics study were referred by community health workers. Inclusion criteria were a diagnosis of schizophrenia or schizo-affective disorder according to the Diagnostic and Statistical Manual of Mental Disorders (DSM-M) criteria, and Xhosa ethnicity 14/4 grandparents reported as being of Xhosa origin). Informed written consent (legal guardians if applicable) was obtained from all participants as per the Institutional Review Board Guidelines of Stellenbosch University.

\section{Assessments}

\section{Diagnostic interviews}

A diagnosis of schizophrenia was confirmed using the Diagnostic Interview for Genetic Studies (2.0). ${ }^{19}$ The interview was conducted in English and/or Xhosa, and supporting information was obtained from collateral sources. The Mini International Neuropsychiatric Interview (MINI) (screen and full (Xhosa version) were administered to establish a diagnosis of OCD and other co-morbid disorders. The MINI/screen consists of 21 screening questions, one or more positive answers to which are followed up with the full MINI interview.

\section{Rating scales}

OCD symptoms were assessed using the Yale Brown Obsessive Compulsive Scale Checklist (CY-BOCS) and the Y-BOCS ${ }^{20}$ (Xhosa version), the most widely used measurement instrument for $O C D$. In addition, a structured questionnaire on hoarding behaviour (developed by Seedat et al., personal communication) consisting of 4 screening questions and 25 detailed questions on the nature and severity of the hoarding symptoms was completed (available on request). Lastly, patients were asked to complete the Clutter Image Rating Scale (CIRS), ${ }^{2}$ which consists of a series of pictures of a room with increasing amounts of clutter. Responses are numbered 1 - 9, with a higher number denoting greater severity.

\section{Data analysis}

Data were analysed using SPSS software (version 13.0). Descriptive statistics (frequencies and means) were calculated.

\section{Results}

The sample consisted of 27 females and 75 males. Age at interview ranged between 20 and 65 years (mean 39.6 years; standard deviation (SD) 10.7 years). On the MINI, 3 subjects met criteria for major depressive disorder, 1 for alcohol abuse, 1 for alcohol dependence and 1 for panic disorder.

Of note, 5 hoarders were identified. One of these was found to be relapsing from his primary illness (schizophrenia), and in view of the unreliability of his self-report, was excluded from the data analysis. Of the remaining 4, all were male, aged between 33 and 46 years. Overall, they scored low on the Y-BOCS and CIRS and did not present with other obsessive-compulsive symptoms on the CY-BOCS (Table I).

\section{Table I. Demographic variables and assessment scores of hoarders}

\begin{tabular}{lccccccc}
\hline \multicolumn{10}{l}{ Table I. Demographic variables and assessment scores of hoarders } \\
\hline Gender & Age (yrs) & Marital status & Employment status & $\begin{array}{l}\text { Highest level } \\
\text { of education } \\
\text { (grade) }\end{array}$ & Y-BOCS score & CIRS score \\
\hline Case 1 & Male & 46 & Married & Disablity grant & 7 & 4 & 1 \\
Case 2 & Male & 42 & Married & Disability grant & 9 & 7 & 13 \\
Case 3 & Male & 33 & Single & Disability grant & 7 & 2 & 3 \\
Case 4 & Male & 46 & Single & Disability grant & 9 & 2 \\
\hline
\end{tabular}


A description of the 4 cases is provided below.

\section{Case 1}

Mr MJR was 46 years old, married, and lived in Khayelitsha. He was employed as a gardener and lived in poor socio-economic circumstances. His highest level of education was grade 7 . On enquiry, he did not describe himself as a hoarder or as someone who had trouble throwing objects away. He also did not think that his 'collecting' was problematic for himself or others. He understood hoarding in terms of 'saving' objects. Over the period he had been hoarding he had saved more than 10 different groups of objects including receipts, clothes, rags, strings, and old radios and television sets, and reported that these objects had material and sentimental value. He had been hoarding for less than 5 years, the objects occupied a room, and he did not consider his hoarding to be an untidy habit. He did not make an effort to resist the compulsion and yielded to it completely and willingly. He thought that the extent of his hoarding had decreased over time. The patient reported that the hoarding behaviour was initiated without any preceding thoughts. With regard to family history, he described having a brother who collected items to 'fix', and thought that he too could have been a hoarder. His mother was a psychiatric patient, but he was unaware of her diagnosis. No other obsessions or compulsions were elicited on the Y-BOCS Checklist, and the patient scored 4/40 on the Y-BOCS and 1 on the CIRS.

\section{Case 2}

Mr MM was 42 years old, married, and lived in Khayelitsha. He was unemployed and his highest level of education was grade 9. He did not consider himself to be a hoarder, and did not think he had trouble throwing things away. He understood hoarding in terms of 'collecting' objects. He 'collected' between 6 and 10 different groups of items including old tins of food, wires, nails and paper items, e.g. cardboard. He had been collecting for less than 2 years and the objects occupied several rooms. Mr MM did not consider his habit to be untidy, and rather thought that he was 'cleaning up the community'. He believed that the objects were of material value although he had not managed to sell anything. He described himself as having 'complete control' over his hoarding, yet experienced extreme incapacitating anxiety or depression when prevented from hoarding. He reported making no effort to resist the compulsion and often yielded to it completely and willingly. He did not report any interference in social functioning but admitted to involving his son in his hoarding. The extent of the hoarding had decreased with time and he reported stopping or limiting hoarding during his psychotic relapses. He had a sibling with a psychiatric illness. No other obsessions and compulsions were present and he scored 8/40 on the Y-BOCS and 1 on the CIRS.

\section{Case 3}

Mr RM was 33 years old, unmarried, and lived in Khayelitsha. He was unemployed and his highest level of education was grade 7. He did not consider himself to be a hoarder; however, he admitted to having difficulty throwing things away. He understood hoarding in terms of collecting objects and failing to discard useful objects. He hoarded 2 to 5 different types of objects including wood, rags, old material and paper items, e.g. newspapers. He had been hoarding for between 5 and 10 years and the objects occupied several rooms. He definitely did not consider it to be an untidy habit, and believed that the objects had actual or practical and material value. However these 'in case' items never came in handy. He admitted to having no control over the hoarding and experienced extreme incapacitating anxiety or depression if prevented from hoarding. However he reported making some effort to resist hoarding. He reported mild interference with his social functioning. There was a sense of relief or satisfaction after a 'hoarding episode' and the extent of the behaviour had remained consistent over time. Exacerbating factors included 'boredom'. He believed that being deprived of affection had contributed to his hoarding. The hoarding was done spontaneously, without preceding thoughts. There was no family history of psychiatric illness that the patient was aware of. Mr RM did not answer positively for any other obsessions or compulsions, and scored 13/40 on the Y-BOCS and 3 on the CIRS.

\section{Case 4}

Mr ZB was 48 years old, unmarried and lived in Khayelitsha. He was also unemployed and his highest level of education was grade 9. He did consider himself to be a hoarder and understood hoarding in terms of 'saving/collecting' objects and failing to discard useful objects. He hoarded between 6 and 10 different types of objects especially paper and metal objects including newspapers, magazines, cardboard, receipts, boxes, iron and copper items. He had been 'saving for between 5 and 10 years and the objects occupied several boxes. He admitted that it was an untidy habit but believed that the objects were of material value. He described himself as having complete control and admitted to experiencing only mild anxiety or depression if prevented from hoarding. He always made an effort to resist this behaviour and he experienced no impairment. He described a sense of relief or satisfaction after a hoarding episode, and 
reported that the extent of the hoarding had stayed the same over time. He could not identify any factors that may have contributed to his hoarding. There was no family history of psychiatric illness that the patient was aware of. He had no other obsessions or compulsions, and scored 2/40 on the Y-BOCS and 2 on the CIRS.

\section{Discussion}

The low yield of hoarding and co-morbid OCD in this sample mirrors the findings of a larger prevalence study of OCD in an independent Xhosa sample. ${ }^{17}$ Although this was a relatively smaller sample, the strengths of this study lie in the careful diagnostic assessment and rating scales that were employed. All diagnostic measures were administered in the patient's first language (Xhosa). Further, this was an ethnically homogeneous sample. The structured questionnaire (Seedat et al., personal communication) used to assess the severity of hoarding behaviour is a locally developed scale which should theoretically allow for more cultural acceptability and suitability for this setting. However, this questionnaire was not administered in Xhosa.

In summary, there is clearly a paucity of data on the prevalence and phenomenology of hoarding in schizophrenia patients. Our finding of a low prevalence of hoarding in the Xhosa population raises two distinct possibilities: first, that this population group may carry some protective factor for OCD and hoarding behaviour; and second, that despite careful evaluation, many of the rating scales may have lacked cultural sensitivity in detecting hoarding in this population. In order to address these points, we propose that the current study be extended to include a control population and that independent CIRS ratings by family members and blinded raters be included.

\section{References}

1. Frost RO, Gross RC. The hoarding of possessions. Behav Res Ther 1993; 31 367-381

2. Frost RO, Hartl TL. A cognitive behavioural model of compulsive hoarding. Behav Res Ther 1996: 34: 341-350.

3. Frost RO, Steketee G, Williams LF. Hoarding: a community health problem. Health Soc Care Community 2000; 8: 229-234.

4. American Psychiatric Association: Diagnostic and Statistical Manual of Mental Disorders, 4th ed. Washington, DC: APA, 1994

5. Frost RO, Krause MS, Steketee G. Hoarding \& OC symptoms. Behav Modif 1996 20:1 16-132.

6. Greenberg D. Compulsive hoarding. Am J Psychother 1987; 41: 409-416.

7. Greenberg D, Witztum E, Levy A. Hoarding as a psychiatric symptom. J Clin Psychiatry $1990 ; 51: 417-421$

8. Claire L, Damecour MD, Maryse C. Hoarding: A symptom, not a syndrome. J Clin Psychiatry 1998; 59: 267-272

9. Frankenburg F. Hoarding in anorexia nervosa. Br J Med Psychol 1984; 57: 57-60.

10. Shafron R, Tallis F. Obsessive compulsive hoarding: a cognitive behavioural approach. Behavioural and Cognitive Psychotherapy 1996; 24: 209-221.

11. Tracy JI, de Leon J, Qureshi G, McCann EM, McGrory A, Josiassen RC. Repetitive behaviours in schizophrenia: a single disturbance or discrete symptoms? Schizophr Res 1996; 20: $221-229$

12. Eisen JL, Baer DA, Pato MT,Venditto TA, Rasmussen SA. OCD in schizophrenia or schizoaffective d/o. Am J Psychiatry 1997; 154: 271-273.

13. Berman I, Kalinowski A, Berman SM, Lenqua J, Green Al. OC symptoms in chronic schizophrenia. Compr Psychiatry 1995; 36: 6-10.

14. Bermanzohn PC, Ponto L, Arlow PB, Pollack S, Stronger R, Siris SG. Hierarchical diagnosis in chronic schizophrenia: a clinical study of co-ocurring syndromes. Schizophr Bull 2000; 26: 517-525.

15. Poyurovsky M, Fuchs $C$, Weizman $A$. OCD in patients with first episode schizophrenia. Am J Psychiatry 1999; 156: 1998-2000

16. Poyurovsky M, Hramenkov S, Isakov V, Rauchverger B, Modai I, Schneidman M, Fuchs C, Weizman A. OCD in hospitalized patients with chronic schizophrenia. Psychiatry Res 2001; 102: 49-57.

17. Niehaus DJH, Koen L, Muller J, et al. OCD - prevalence in Xhosa speaking schizophrenia patients. S Afr Med J 2005; 95: 120-122.

18. Polimeni J, Reiss JP, Sareen J. Could OCD have originated as a group selected adaptive trait in traditional societies? Med Hypotheses 2005; 65: 655-664

19. Nurnberger II jun., Blehar MC, Kaufmann CA, et al. Diagnostic interview for genetic studies. Rationale, unique features, and training. NIMH Genetics Initiative. Arch Gen Psychiatry 1994; 51 : 849-859

20. Goodman WK, Price LH, Rasmussen SA, et al. The Yale Brown Obsessive Compulsive Scale. I. Development, use and reliaility. Arch Gen Psychiatry 1989; 46: 1006-1011. 